\title{
Electrochemiluminescent Detection of Hydrogen Peroxide via Some Luminol Imide Derivatives with Different Substituent Groups
}

\author{
Tifeng Jiao, ${ }^{1,2}$ Qinqin Huang, ${ }^{1}$ Yong Xiao, ${ }^{3}$ Xihai Shen, ${ }^{1,4}$ Jingxin Zhou, ${ }^{1}$ and Faming Gao ${ }^{1}$ \\ ${ }^{1}$ Hebei Key Laboratory of Applied Chemistry, School of Environmental and Chemical Engineering, Yanshan University, \\ Qinhuangdao 066004, China \\ ${ }^{2}$ State Key Laboratory of Solid Lubrication, Lanzhou Institute of Chemical Physics, Chinese Academy of Sciences, \\ Lanzhou 730000, China \\ ${ }^{3}$ Environmental Protection Sciences Research Institute of Qinhuangdao City, Qinhuangdao 066001, China \\ ${ }^{4}$ College of Physics and Chemistry, Hebei Normal University of Science and Technology, Qinhuangdao 066004, China
}

Correspondence should be addressed to Tifeng Jiao; tfiao@ysu.edu.cn

Received 28 September 2013; Accepted 21 October 2013

Academic Editor: Xinqing Chen

Copyright (c) 2013 Tifeng Jiao et al. This is an open access article distributed under the Creative Commons Attribution License, which permits unrestricted use, distribution, and reproduction in any medium, provided the original work is properly cited.

Some luminol imide derivatives with different substituent groups have been designed and synthesized. Their electrochemiluminescence properties have been measured with a view to developing new biosensors. The ECL response to hydrogen peroxide in the presence of these luminescent derivatives has been investigated taking into account crucial factors such as the applied potential value, injection volume of hydrogen peroxide, and the substituent groups in molecular structures. The experimental data demonstrated that the substituent groups in these imide derivatives can have a profound effect upon the ECL abilities of these studied compounds. The present research work affords new and useful exploration for the design and development of new soft matter for ECL biosensors with luminol functional groups.

\section{Introduction}

In recent several decades, in the development of biomimetic optoelectronic nanosensors, luminol is considered as an efficient system in chemiluminescence (CL) and electrochemiluminescence (ECL) measurements for the detection of hydrogen peroxide [1-3]. It is well-known that luminol CL in the presence of hydrogen peroxide can be produced through the action of a chemical catalyst like ferricyanide or a biocatalyst such as peroxidase. On the other hand, the application of a potential to oxidize luminol can successfully replace a catalyst to provoke luminol electrogenerated chemiluminescence with inherent high sensitivities and wide linear working ranges [4-8]. For this electrochemical process, as shown in Figure 1, screen-printed electrodes have been demonstrated to trigger luminol ECL as efficiently as glassy carbon macroelectrodes [9-12].
In the previous work, we reported the design and synthesis of functional luminol derivatives with different substituted groups and investigated the interfacial assembly of these compounds with different methods [13-15]. At the same time, their potential for ECL measurement has been demonstrated first [16]. Meanwhile, their interfacial behavior and the morphologies of pure or mixed monolayers used to develop the biomimetic membrane were investigated [17]. The introduction of different substituted groups into those functional compounds can lead to new conjugated structures and new properties are expected. In addition, some luminol imide derivatives with different alkyl substituent chains could form different organogels in various organic solvents [18]. Characterization of the organogels revealed different structures of the aggregates in the gels. We have investigated the effect of the length and number of alkyl substituent chains in gelators 


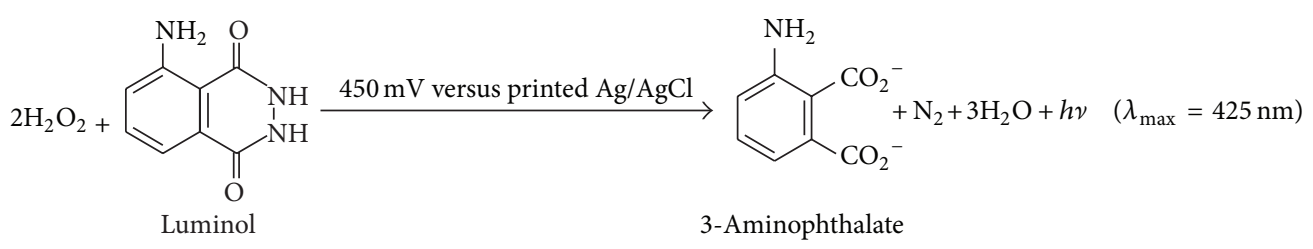

FIGURE 1: Electrochemiluminescence (ECL) reaction of luminol in the presence of hydrogen peroxide.<smiles>O=C(Nc1cccc2c(=O)[nH][nH]c(=O)c12)c1ccccc1</smiles>

Lu-Ben<smiles>O=C(Nc1cccc2c(=O)[nH][nH]c(=O)c12)c1ccc(C(=O)NC2CC=Cc3c2c(=O)[nH][nH]c3=O)cc1</smiles>

Lu-P-Ben<smiles>O=C(Nc1cccc2c(=O)[nH][nH]c(=O)c12)c1cc(C(=O)Nc2cccc3c(=O)[nH][nH]c(=O)c23)cc(C(=O)Nc2cccc3c(=O)[nH][nH]c(=O)c23)c1</smiles><smiles>O=C(Nc1cccc2c(=O)[nH][nH]c(=O)c12)c1cccc2ccccc12</smiles>

Lu-Np<smiles>[R20]c1cc(C(=O)Nc2cccc3c(=O)[nH][nH]c(=O)c23)cc([R20])c1OCC</smiles><smiles>CCCCCOc1ccc(C(=O)Nc2cccc3c(=O)[nH][nH]c(=O)c23)cc1</smiles>

$\mathrm{R}=-\mathrm{C}_{18} \mathrm{H}_{37} \mathrm{~T}-\mathrm{C} 18-\mathrm{Lu}$

$\mathrm{R}=-\mathrm{C}_{16} \mathrm{H}_{33} \mathrm{~T}-\mathrm{C} 16-\mathrm{Lu}$

S-C16-Lu<smiles>O=C(CCCCCCCCCC(=O)Nc1cccc2c(=O)[nH][nH]c(=O)c12)Nc1cccc2c(=O)[nH][nH]c(=O)c12</smiles>

$\mathrm{R}=-\mathrm{C}_{14} \mathrm{H}_{29}$ T-C14- $\mathrm{Lu}$<smiles>CCCCCCCOc1ccc(C(=O)Nc2cccc3c(=O)[nH][nH]c(=O)c23)cc1</smiles>

Lu-Bis-C10<smiles>CC(C)CCCC(C)C1CCC2C3CC=C4C[C@@H](OC(=O)Nc5cccc6c(=O)[nH][nH]c(=O)c56)CC[C@]4(C)C3CC[C@]12C</smiles>

Lu-Dan

FIGURE 2: Molecular structures and abbreviations of present luminol derivatives with different substituent groups.

on the microstructures of such organogels in detail and found different kinds of hydrogen bond interactions between amide groups.

As an extension work, we reported here the electrochemiluminescence properties of functional luminol derivative containing different substituted groups with a view to developing new biosensors. The ECL response to hydrogen peroxide in the presence of these luminescent derivatives has been investigated taking into account crucial factors such as the applied potential value, injection volume of hydrogen peroxide, and the substituent groups in molecular structures. The present results may give useful clues for the design and development of new ECL biosensors with luminol functional groups. 


\section{Experiments}

2.1. Reagents. All materials, luminol, cholesteryl chloroformate, benzoyl chloride, 1-naphthoyl chloride, methyl 3,4,5trihydroxybenzoate, 4-hydroxybenzenecarboxylic acid, and other used reagents were obtained commercially from Alfa Aesar Chemicals, TCI Shanghai Chemicals, Sinopharm Chemical Reagent Co., Ltd (China), and used without further purification. All used solvents were obtained from Beijing Chemicals and were distilled before use. Deionized water was used in all cases. 4-Alkyloxy-benzoic acid and 3,4,5tris(alkyloxy)benzoic acid with different alkyl substituent chains were synthesized in our laboratory according to our previous report [19] and confirmed by ${ }^{1} \mathrm{H}$ NMR. These luminol derivatives were synthesized by the reaction of the corresponding chloride precursors with luminol according to slight modifications of procedures already reported in the literature $[20,21]$. The final products and their abbreviations are shown in Figure 2, which were confirmed by ${ }^{1} \mathrm{H}$ NMR.

2.2. Apparatus. The ECL setup was described previously in our reports [17]. The screen-printed sensor $(4 \mathrm{~cm} * 0.6 \mathrm{~cm})$ was comprised of a graphite working electrode $\left(0.19 \mathrm{~cm}^{2}\right)$ and a printed $\mathrm{Ag} / \mathrm{AgCl}$ reference electrode $\left(0.30 \mathrm{~cm}^{2}\right)$. The screen-printed sensor is connected to a potentiostat. A liquid core optical fiber connected at one end to the photomultiplier tube of a luminometer faced the electrode. Electrochemiluminescence measurements in arbitrary units (a.u.) were recorded with a graphic recorder.

2.3. Characterization. Stock solutions of luminol and present luminol derivatives were dispersed into PBS buffer ( $\mathrm{pH} 8.0)$ under vigorous stirring prior to use to avoid any precipitation. The screen-printed sensor was immersed in a glass cuvette protected by black paper to avoid light and filled with a PBS buffer ( $\mathrm{pH}$ 8.0) containing luminol or its derivatives. After the application of a cyclic voltammetry potential (between $450 \mathrm{mV}$ and $850 \mathrm{mV}$ versusprinted $\mathrm{Ag} / \mathrm{AgCl}$ ) and stabilization of the luminescent background signal, the ECL reaction was initiated by the injection of hydrogen peroxide solution in the buffer-filled cell. A steady-state light signal was reached after ca. $1 \mathrm{~min}$. The working condition (PBS buffer, $\mathrm{pH} 9.0$, $25^{\circ} \mathrm{C}$ ) was optimized for ECL detection to perform below measurements.

\section{Results and Discussion}

3.1. Effect of Some Factors on ECL Detection. It was reported previously that the screen-printed electrodes can be efficiently used in PBS buffer ( $\mathrm{pH}$ 8.0). In addition, a cyclic voltammetry potential of $-0.40 \mathrm{~V} \sim-0.80 \mathrm{~V}$ versusprinted $\mathrm{Ag} / \mathrm{AgCl}$ was described as an optimized value for hydrogen peroxide-detecting optical fiber biosensors based on luminol ECL. In the present work, the best optimal potential value for ECL of luminol derivatives is required to be determined. Consequently, the relationship of ECL intensity as a function of potential was investigated, as shown in Figure 3. For the case of T-C14-Lu, $30 \mathrm{uL}$ (50 uM) hydrogen peroxide solution

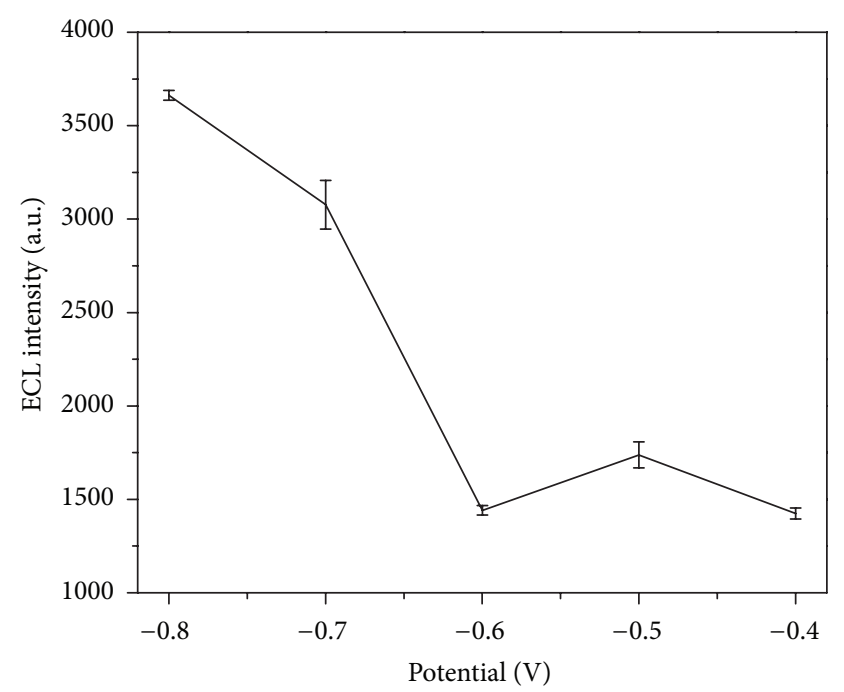

FIGURE 3: ECL intensity as a function of potential for T-C14Lu. The measurements were performed in PBS buffer $(\mathrm{pH} 8.0)$ containing $50 \mathrm{uM}$ of T-C14-Lu. The ECL reaction was initiated by sequential injection of $30 \mathrm{uL}$ hydrogen peroxide solution in the working medium.

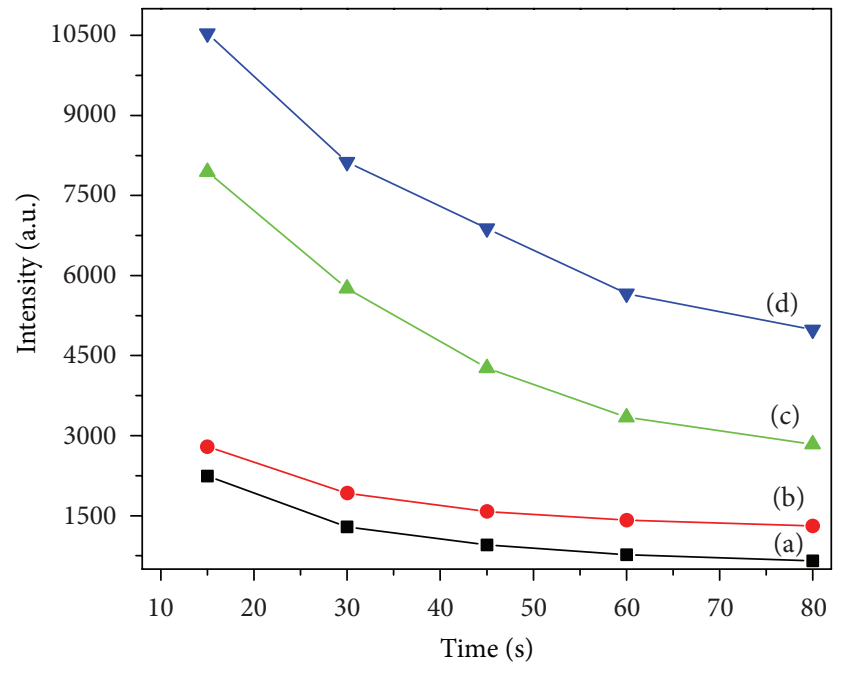

FIgURE 4: Calibration curves for hydrogen peroxide detection. The measurements were performed in PBS buffer ( $\mathrm{pH}$ 8.0) containing Lu-P-Ben at concentrations of $50 \mathrm{uM}$. The ECL reaction was initiated by sequential injections of hydrogen peroxide in the working medium at volumes of $10 \mathrm{uL}$ (a), $20 \mathrm{uL}$ (b), $30 \mathrm{uL}$ (c), and $40 \mathrm{uL}$ (d), respectively.

was injected to the working medium. In the same concentration of hydrogen peroxide solution, it can be observed that with the increment of potential value from $-0.45 \mathrm{~V}$ to $-0.80 \mathrm{~V}, \mathrm{ECL}$ intensity increased. So, the value of $0.80 \mathrm{~V}$ was preferred to measure other present systems.

In addition, at a potential value of $-0.80 \mathrm{~V}$, the ECL detection with different concentrations of hydrogen peroxide detection was performed for Lu-P-Ben, as shown in Figure 4. The measurements were performed in PBS buffer $(\mathrm{pH} 8.0)$ 


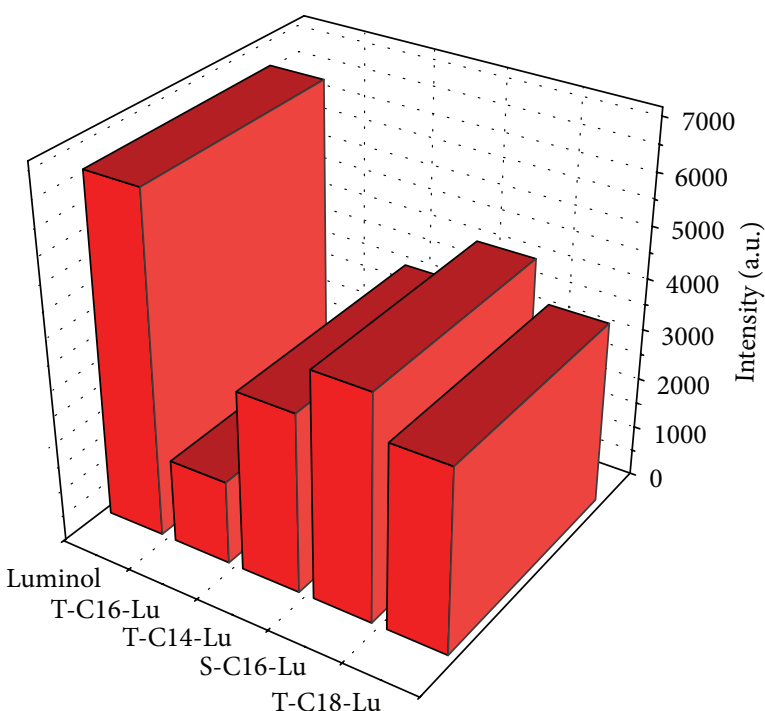

(a)

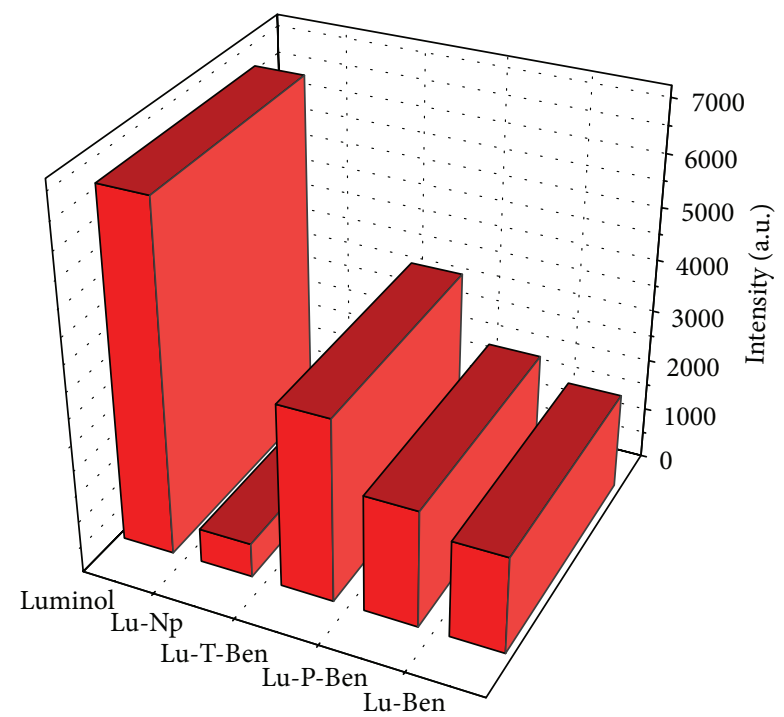

(b)

FIGURE 5: Calibration columns for ECL detection of hydrogen peroxide. The measurements were performed in PBS buffer (pH 8.0). The ECL reaction was initiated by sequential injection of $30 \mathrm{uL}$ hydrogen peroxide in the working medium.

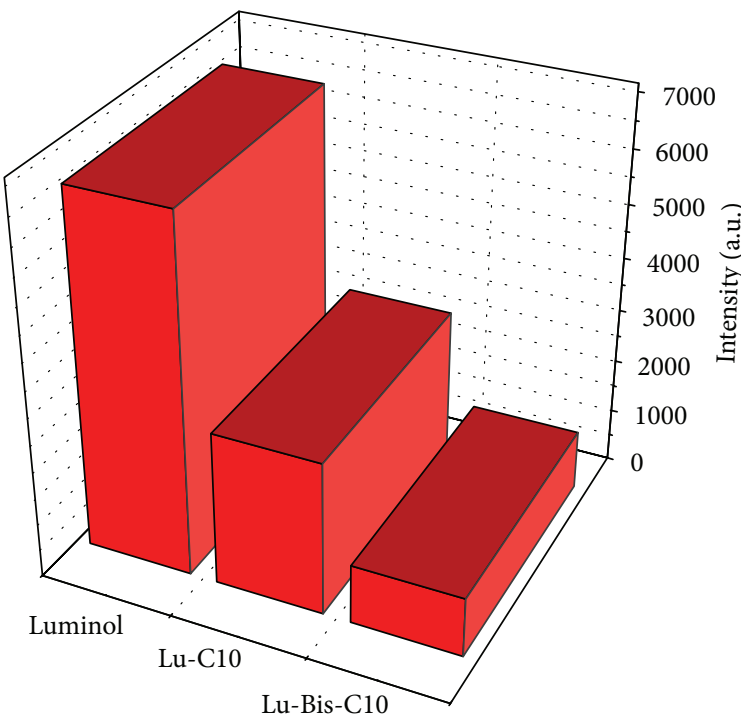

(a)

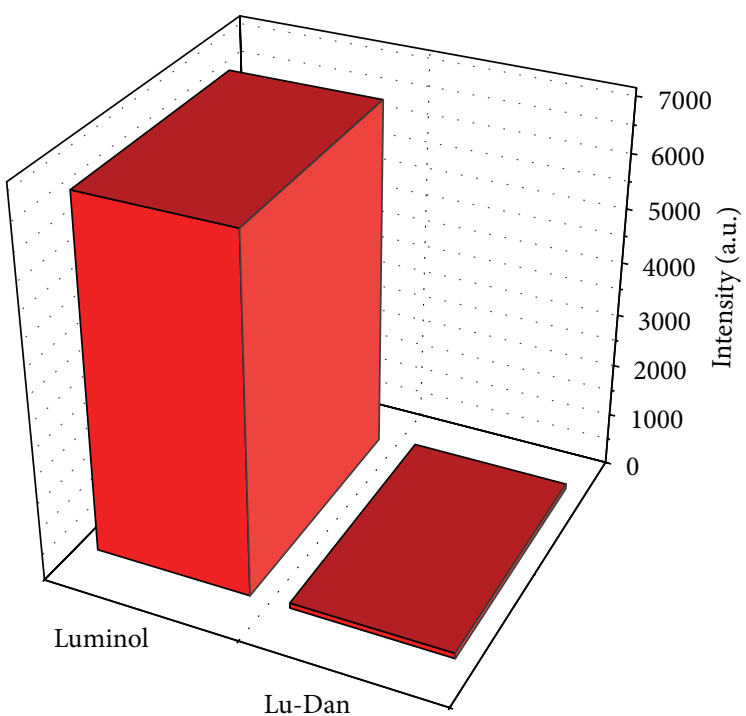

(b)

FIGURE 6: Calibration columns for ECL detection of hydrogen peroxide. The measurements were performed in PBS buffer (pH 8.0). The ECL reaction was initiated by sequential injection of $30 \mathrm{uL}$ hydrogen peroxide in the working medium.

containing Lu-P-Ben at concentrations of $50 \mathrm{uM}$. The ECL reaction was initiated by sequential injections of hydrogen peroxide in the working medium at different volumes. It can be observed that with the increment of injection volumes of hydrogen peroxide in the working medium, ECL intensity increased with nonlinear style. The ECL intensity is not strong enough with low injection volumes due to the delay in the dispersion process. So, the injection volume of $30 \mathrm{uL}$ for hydrogen peroxide was chosen to measure the next research work.

Moreover, ECL measurements of luminol derivatives with different substituted groups were compared, as shown in
Figures 5 and 6 , respectively. The measurements were performed in PBS buffer ( $\mathrm{pH}$ 8.0). The ECL reaction was initiated by sequential injection of $30 \mathrm{uL}$ hydrogen peroxide in the working medium. Firstly, the ECL intensities of luminol derivatives with single/multialkyl chains connected to benzene ring substituted groups were compared. The results showed that among the present four compounds, S-C16-Lu with single alkyl chain showed better ECL property that of the than other compounds with multialkyl chains. In addition, as for the present luminol derivatives with aromatic substituted groups, Lu-T-Ben with C3-symmetrical skeleton showed 
better ECL behaviors than those of the other compounds with phenyl or naphthyl substituted groups. Interestingly, it should be noted that Lu-Dan with large cholesteryl substituted group showed a weaker ECL property that of the than luminol. For all luminol derivatives, the ECL properties showed a more decrement tendency than that of the luminol, which may be due to the weak solubility, poor dispersion in water, and effect of substituted groups.

3.2. Discussion. In our previous work, we reported the synthesis and characterization of some luminol derivatives containing aromatic/alkyl substituted groups [13, 14]. The introduction of different aromatic substituted groups into the present functional compounds can lead to larger conjugated structures and new properties are expected. At the same time, the size and rigidity/flexibility of functional amphiphiles could regulate the potential properties both in solution and at interface, which demonstrated the advantage of precise molecular design. In addition, we have found that most compounds could form different organogels in various organic solvents [18]. We have investigated the effect of the length and number of alkyl substituent chains in gelators on the microstructures of organogels in detail and found different kinds of hydrogen bond interactions between amide groups. Therein, the alkyl substituent chains in luminol derivatives had played a very important role in regulating the assembly modes and nanostructures in these organogels. Now, the ECL properties generated by the present luminol derivatives in the presence of choline chloride and choline oxidase are under investigation to display the relationship between the molecular structures, as-formed nanostructures, and ECL sensors [22].

\section{Conclusions}

Some luminol imide derivatives with different substituent groups have been designed and synthesized. Their electrochemiluminescence properties have been measured with a view to developing new biosensors. The ECL response to hydrogen peroxide in the presence of these luminescent derivatives has been investigated taking into account crucial factors such as the applied potential value, injection volume of hydrogen peroxide, and the substituent groups in molecular structures. The experimental data demonstrated that the substituent groups in these imide derivatives can have a profound effect upon the ECL abilities of these studied compounds. The present research work affords new and useful exploration for the design and development of new soft matter for ECL biosensors with luminol functional groups.

\section{Conflict of Interests}

The authors declare that they have no direct financial relation with the commercial identities mentioned in this paper that might lead to a conflict of interests for any of them.

\section{Acknowledgments}

This work was financially supported by the National Natural Science Foundation of China (Grant nos. 20903078,
21207112), the Natural Science Foundation of Hebei Province (Grant nos. B2012203060, B2013203108), the China Postdoctoral Science Foundation (Grant nos. 2011M500540, 2012M510770, and 2013T60265), the Science Foundation for the Excellent Youth Scholars from Universities and Colleges of Hebei Province (Grant nos. Y2011113, YQ2013026), the Scientific Research Foundation for Returned Overseas Chinese Scholars of Hebei Province (Grant no. 2011052), and the Open Foundation of State Key Laboratory of Solid Lubrication (Grant no. 1002).

\section{References}

[1] B. Leca and L. J. Blum, "Luminol electrochemiluminescence with screen-printed electrodes for low-cost disposable oxidasebased optical sensors," Analyst, vol. 125, no. 5, pp. 789-791, 2000.

[2] S. Sakura, "Electrochemiluminescence of hydrogen peroxideluminol at a carbon electrode," Analytica Chimica Acta, vol. 262, no. 1, pp. 49-57, 1992.

[3] C. A. Marquette and L. J. Blum, "Electro-chemiluminescent biosensing," Analytical and Bioanalytical Chemistry, vol. 390, no. 1, pp. 155-168, 2008.

[4] V. C. Tsafack, C. A. Marquette, B. Leca, and L. J. Blum, "An electrochemiluminescence-based fibre optic biosensor for choline flow injection analysis," Analyst, vol. 125, no. 1, pp. 151-155, 2000.

[5] A. Sassolas, L. J. Blum, and B. D. Leca-Bouvier, "Electrogeneration of polyluminol and chemiluminescence for new disposable reagentless optical sensors," Analytical and Bioanalytical Chemistry, vol. 390, no. 3, pp. 865-871, 2008.

[6] S. Godoy, B. Leca-Bouvier, P. Boullanger, L. J. Blum, and A. P. Girard-Egrot, "Electrochemiluminescent detection of acetylcholine using acetylcholinesterase immobilized in a biomimetic Langmuir-Blodgett nanostructure," Sensors and Actuators B, vol. 107, no. 1, pp. 82-87, 2005.

[7] L. J. Blum, S. M. Gautier, and P. R. Coulet, "Design of luminescence photobiosensors," Journal of Bioluminescence and Chemiluminescence, vol. 4, no. 1, pp. 543-550, 1989.

[8] C. A. Marquette and L. J. Blum, "Luminol electrochemiluminescence-based fibre optic biosensors for flow injection analysis of glucose and lactate in natural samples," Analytica Chimica Acta, vol. 381, no. 1, pp. 1-10, 1999.

[9] L. Zhu, Y. Li, and G. Zhu, "A novel flow through optical fiber biosensor for glucose based on luminol electrochemiluminescence," Sensors and Actuators B, vol. 86, no. 2-3, pp. 209-214, 2002.

[10] S. Godoy, S. Violot, P. Boullanger et al., "Kinetics study of Bungarus fasciatus venom acetylcholinesterase immobilised on a Langmuir-Blodgett proteo-glycolipidic bilayer," ChemBioChem, vol. 6, no. 2, pp. 395-404, 2005.

[11] A. P. Girard-Egrot, S. Godoy, and L. J. Blum, "Enzyme association with lipidic Langmuir-Blodgett films: interests and applications in nanobioscience," Advances in Colloid and Interface Science, vol. 116, no. 1-3, pp. 205-225, 2005.

[12] P. Boullanger, M.-R. Sancho-Camborieux, M.-N. Bouchu, L. Marron-Brignone, R. M. Morelis, and P. R. Coulet, "Synthesis and interfacial behavior of three homologous glycero neoglycolipids with various chain lengths," Chemistry and Physics of Lipids, vol. 90, no. 1-2, pp. 63-74, 1997.

[13] T. Jiao, Y. Xing, and J. Zhou, "Synthesis and characterization of functional cholesteryl substituted luminol derivative," Materials Science Forum, vol. 694, pp. 565-569, 2011. 
[14] T. F. Jiao, Y. Y. Xing, J. X. Zhou, and W. Wang, "Synthesis and characterization of some functional luminol derivatives with aromatic substituted groups," Advanced Materials Research, vol. 197-198, pp. 606-609, 2011.

[15] T. Jiao, B. D. Leca-Bouvier, P. Boullanger, L. J. Blum, and A. P. Girard-Egrot, "Phase behavior and optical investigation of two synthetic luminol derivatives and glycolipid mixed monolayers at the air-water interface," Colloids and Surfaces A, vol. 321, no. 1-3, pp. 137-142, 2008.

[16] T. Jiao, B. D. Leca-Bouvier, P. Boullanger, L. J. Blum, and A. P. Girard-Egrot, "Electrochemiluminescent detection of hydrogen peroxide using amphiphilic luminol derivatives in solution," Colloids and Surfaces A, vol. 321, no. 1-3, pp. 143-146, 2008.

[17] T. Jiao, B. D. Leca-Bouvier, P. Boullanger, L. J. Blum, and A. P. Girard-Egrot, "A chemiluminescent Langmuir-Blodgett membrane as the sensing layer for the reagentless monitoring of an immobilized enzyme activity," Colloids and Surfaces A, vol. 354, no. 1-3, pp. 284-290, 2010.

[18] T. F. Jiao, Q. Q. Huang, Q. R. Zhang, D. B. Xiao, J. X. Zhou, and F. M. Gao, "Self-assembly of organogels via new luminol imide derivatives: diverse nanostructures and substituent chain effect," Nanoscale Research Letters, vol. 8, no. 1, article 278, 2013.

[19] H. Yang, T. Yi, Z. Zhou et al., "Switchable fluorescent organogels and mesomorphic superstructure based on naphthalene derivatives," Langmuir, vol. 23, no. 15, pp. 8224-8230, 2007.

[20] Y. Omote, T. Miyake, S. Ohmori, and N. Sugiyama, "The chemiluminescence of acyl luminols," Bulletin of the Chemical Society of Japan, vol. 39, no. 5, pp. 932-935, 1966.

[21] Y. Omote, T. Miyake, S. Ohmori, and N. Sugiyama, "The chemiluminescence of luminol and acetyl-luminol," Bulletin of the Chemical Society of Japan, vol. 40, no. 5, pp. 899-903, 1967.

[22] A. P. Girard-Egrot, C. A. Marquette, and L. J. Blum, "Biomimetic membranes and biomolecule immobilisation strategies for nanobiotechnology applications," International Journal of Nanotechnology, vol. 7, no. 4-8, pp. 753-780, 2010. 

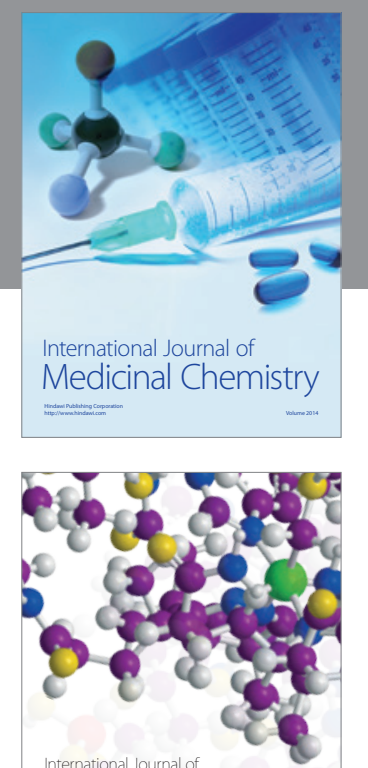

\section{Carbohydrate} Chemistry

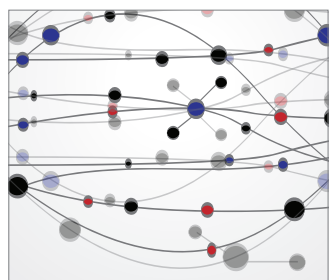

The Scientific World Journal
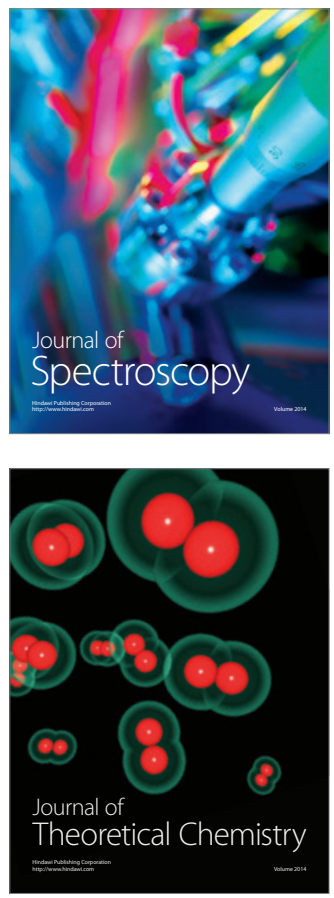
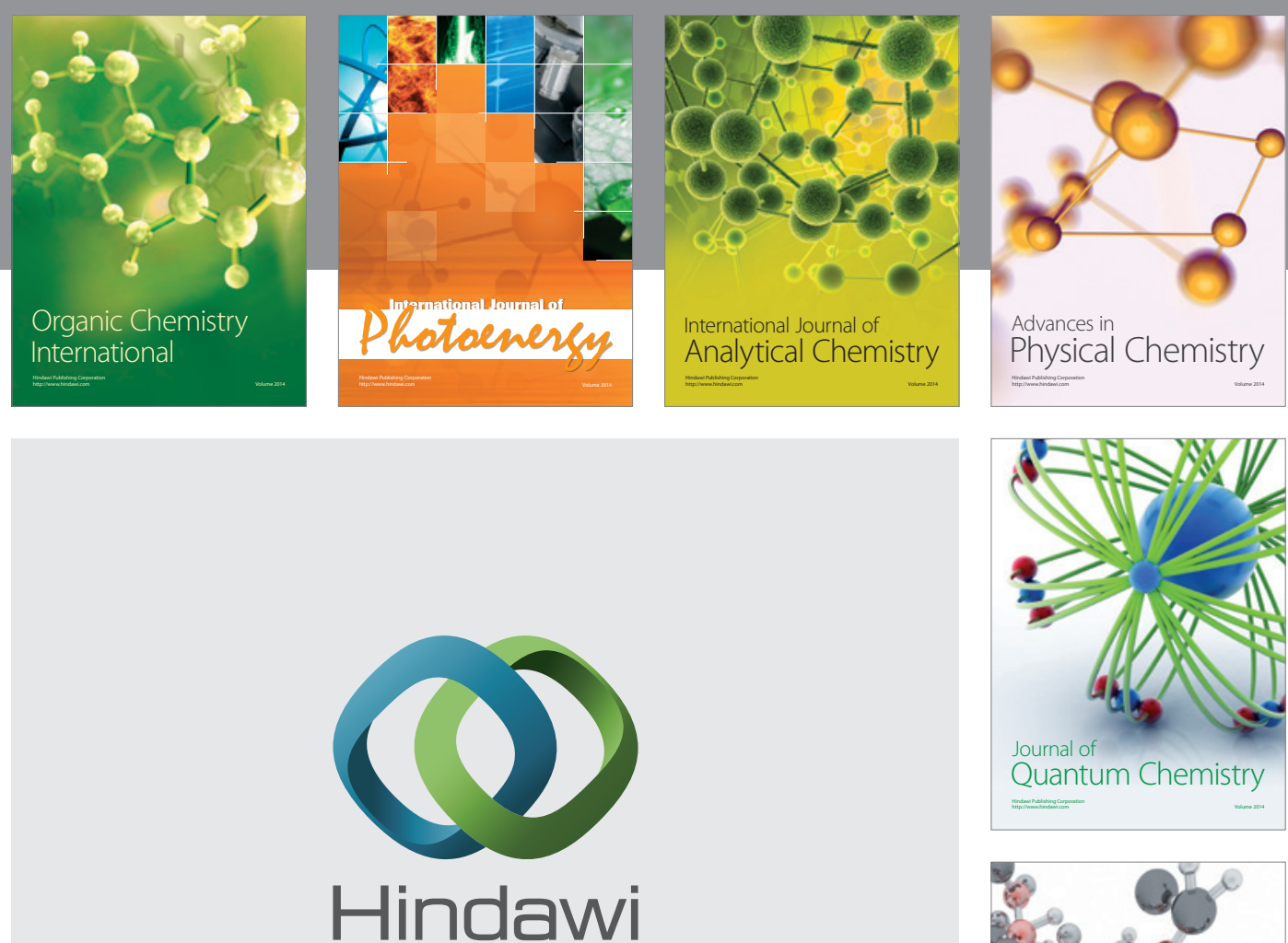

Submit your manuscripts at

http://www.hindawi.com

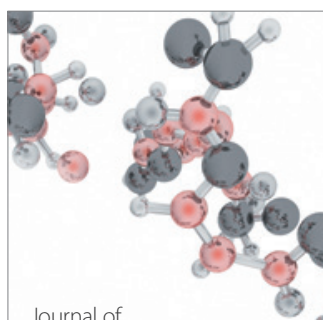

Analytical Methods

in Chemistry

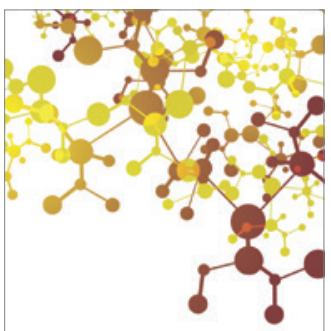

Journal of

Applied Chemistry

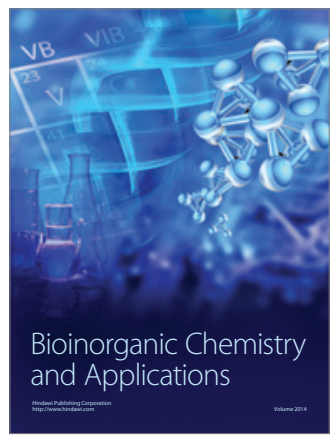

Inorganic Chemistry
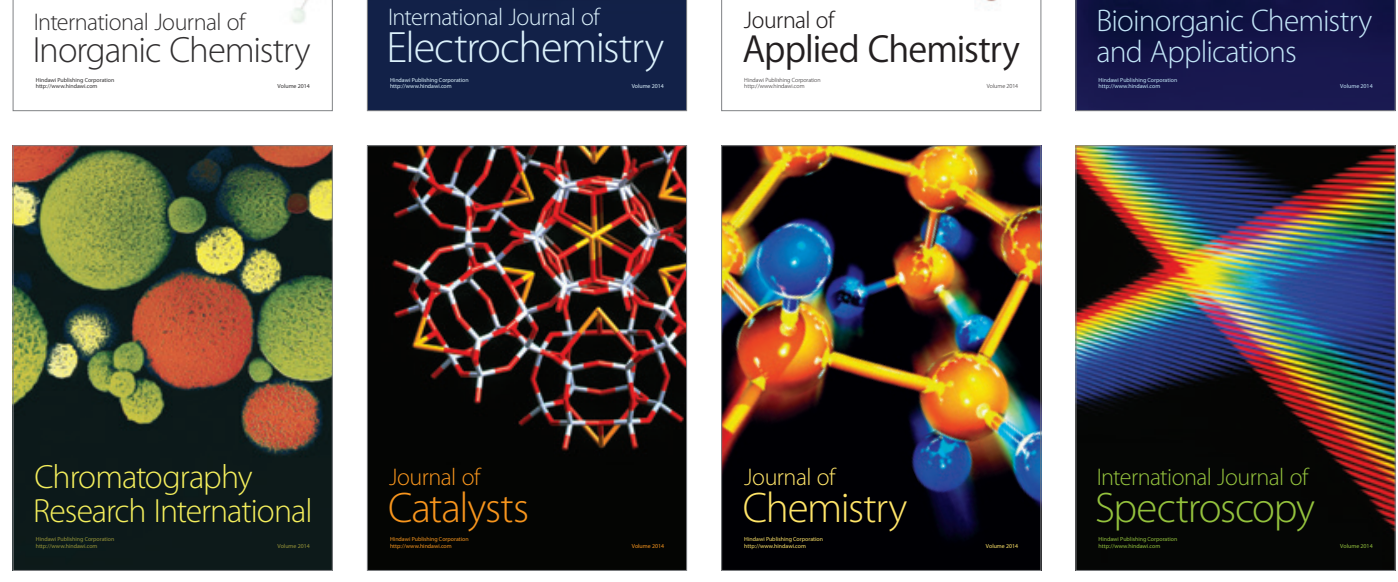